\title{
Las lecciones de Chernóbil: Ciencia y tecnología en la sociedad global y el proyecto cosmopolita
}

Willy Soto Acosta'

Fecha de recepción: 25 de febrero, 2011

Fecha de aprobación: 13 de agosto del 201 I

Soto, W. Las lecciones de Chernóbil: Ciencia y tecnología en la sociedad global y el proyecto cosmopolita. Tecnología en Marcha. Vol. 25, N I.

Enero-Marzo 2012 Pág 70-76 Artículo informativo 


\section{Palabras clave}

Accidente de Chernóbil, ciencia y tecnología, globalización, cosmopolitismo, sociedad del riesgo.

\section{Resumen}

El artículo parte de las tres grandes lecciones que dejó la tragedia de Chernóbil. En primer lugar, que las invenciones científicas y tecnológicas pueden escapar del control humano y pueden llegar a representar un riesgo, es decir, un potencial negativo contra la misma humanidad. Segundo, que la ciencia y la tecnología pueden volverse contra el mismo género humano si no son enmarcadas dentro de un proyecto cosmopolita. Tercero, Chernóbil demostró que los riesgos ecológicos no respetan fronteras y amenazan a casi la totalidad del planeta Tierra.

El trabajo enfoca la problemática desde la teoría de la sociedad del riesgo global y enfatiza la necesidad de un desarrollo científico y tecnológico en función de la vida (humana, animal, vegetal) y no de los intereses de élites políticas y económicas o del poderío de los Estados.

\section{Key words}

Chernobyl accident, science and technology, globalization, cosmopolitism, risk society.

\begin{abstract}
The article is based on the three great lessons given by the Chernobyl tragedy. The first lesson is that scientific and technological inventions can get out of the human control and they can become a risk, in others words, they can become a negative potential against humanity.

The second lesson is that science and technology can work against human race if they are not framed within a Cosmopolitan Project. And the third one is that the tragedy in Chernobyl demonstrated that the ecological risks do not respect borders and threaten almost the entire planet Earth.

The article focuses on this problematic situation based on the Global Society Risk theory, and emphasizes the need for a scientific and technological development that works in benefit of human, animal and vegetal life, and not of the elites' political and economic interests and/or of the States power.
\end{abstract}

"Los peligros globales ponen en cuestión la supervivencia de la humanidad y abren a través de este cuestionamiento oportunidades globales de acción... Saber que todas las tragedias de nuestro tiempo son de procedencia y alcance global origina un horizonte de experiencias y esperanzas cosmopolita. Cada vez comprendemos mejor que vivimos en un contexto de responsabilidad global del que nadie puede salir" (Beck, 2004: 383).

\section{Introducción}

El 26 de abril de 1986 fue un día histórico: se produjo un accidente nuclear en la Central Nuclear de Chernóbil, Ucrania, entonces parte integrante de la antigua Unión Soviética.

Con la II Guerra Mundial, el mundo experimentó el horror del efecto nuclear en las poblaciones, con las bombas atómicas lanzadas en Japón. Lo nuevo con Chernóbil no fue solamente el poderío nuclear del incidente en cuanto a la cantidad de material radiactivo soltado al ambiente (ciento de veces mayor que una bomba atómica), sino que fue un accidente. Aunque el mundo temía, en plena Guerra
Fría, un ataque deliberado de una super-potencia (Unión Soviética, Estados Unidos) contra la otra, o bien un ataque atómico en sus zonas geo-políticas de influencia, el estallido nuclear no fue intencional.

La tragedia de Chernóbil dejó tres grandes lecciones:

a) Las invenciones científicas y tecnológicas pueden escapar al control humano y pueden llegar a representar un riesgo, es decir, un potencial negativo contra la misma humanidad.

b) Corolario de lo anterior, este accidente vino a verificar lo que ya se sabía: como Espada de 
Damocles, la ciencia y la tecnología puede volverse contra el mismo género humano si no son guiadas por una orientación humanista, digámoslo de una vez, sino son enmarcadas dentro de un proyecto cosmopolita.

c) A diferencia del estallido de las bombas atómicas en Japón que tuvieron un efecto destructor relativamente focalizado, Chernóbil demostró que los riesgos ecológicos no respetan fronteras y amenazan a casi la totalidad del planeta Tierra.

Es en este contexto que cobra relevancia la teoría de la sociedad del riesgo global y el replanteamiento de los valores que deben guiar el desarrollo de la ciencia y la tecnología.

\section{I. ¿Qué es la globalización?}

El sociólogo alemán Ulrich Beck, con sus obras -principalmente La sociedad del riesgo, ha contribuido a un nuevo enfoque sociológico que intenta comprender las amenazas por las que atraviesa la humanidad a partir del último cuarto del siglo $X X$.

La "teoría de la sociedad del riesgo global", como se le denomina a este cuerpo teórico propuesto por Beck, es una teoría que se origina en el contexto de la globalización, pero, a la vez, constituye una teoría acerca de esta etapa histórica.

Beck emplea el término "globalismo" para referirse a la ideología que propugna la globalización neoliberal como camino inevitable y conveniente para la humanidad. Posteriormente, distingue entre "globalidad" y "globalización":

\section{Globalidad}

En sus palabras, "La globalidad significa lo siguiente: hace ya bastante tiempo que vivimos en una sociedad mundial, de manera que la tesis de los espacios cerrados es ficticia" (1988a, p. 28).

La globalidad nos recuerda el hecho de que, a partir de ahora, nada de cuanto ocurra en nuestro planeta podrá ser un suceso localmente delimitado, sino que todos los descubrimientos, victorias y catástrofes afectarán a todo el mundo y que todos debemos reorientar y reorganizar nuestras vidas y quehaceres, así como nuestras organizaciones e instituciones, a lo largo del eje "localglobal"' (Beck, 1988a, p.30).

La globalidad se manifiesta en ocho fenómenos palpables:

I. El ensanchamiento del campo geográfico y la creciente densidad del intercambio internacional, así como el carácter global de la red de mercados financieros y del poder cada vez mayor de las multinacionales.

2. La revolución permanente en el terreno de la información y las tecnologías de la comunicación.

3. La exigencia, universalmente aceptada, de respetar los derechos humanos.

4. Las corrientes icónicas de las industrias globales de la cultura.

5. La política mundial posinternacional y policéntrica: junto a los gobiernos hay cada vez más actores internacionales con cada vez mayor poder (multinacionales, organizaciones no-gubernamentales, Naciones Unidas).

6. El problema de la pobreza global.

7. El problema de los daños y atentados ecológicos globales.

8. El problema de los conflictos transculturales en un lugar concreto (Beck, 1988a, pp. 29-30).

\section{Globalización}

Al dejar en claro lo que constituye la globalidad, "...la globalización significa los procesos en virtud de los cuales los Estados nacionales soberanos se entremezclan e imbrican mediante actores transnacionales y sus respectivas probabilidades de poder, orientaciones, identidades y entramados varios" (Beck, 1988a, p.29).

En otras palabras," (...) el concepto de globalización se puede describir como un proceso (...) que crea vínculos y espacios sociales transnacionales, revaloriza culturas locales y trae a primer plano terceras culturas - ' un poco de esto, otro poco de eso, tal es la manera en que las novedades llegan al mundo' (Salman Rushdie) -" (Beck, 1988a, p.30). 


\section{La globalidad y la globalización constituyen una sociedad del riesgo: el riesgo es lo característico de la dinámica social}

La "teoría de la sociedad del riesgo global" parte de las siguientes premisas:

a. Las amenazas son fundamentalmente ecológicas, aunque estén condicionadas por motivos políticos (peligro nuclear, actos terroristas), sociales (desigualdad social y miseria que redunda en una sobre-explotación de los recursos naturales), económicos (efectos ambientales -calentamiento global, entre otros- del uso del petróleo; sobre-explotación y contaminación de los suelos producido por el ansia de obtener ganancias crecientes).

Debido a esto, existe un continum entre naturaleza y sociedad:

... la noción de la sociedad del riesgo mundial es pertinente en un mundo que se puede caracterizar por una pérdida de distinción clara entre naturaleza y cultura. Si hoy día hablamos de naturaleza, hablamos de cultura, y si hablamos de cultura, hablamos de naturaleza. Nuestra concepción de naturaleza y cultura como dos mundos aparte, que está íntimamente ligada al pensamiento moderno, no puede reconocer que estamos construyendo, actuando y viviendo en un mundo artificialmente construido por la civilización cuyas características están más allá de estas distinciones, que todavía dominan nuestra manera de pensar. La pérdida de fronteras entre estos dos ámbitos no es solo consecuencia de la industrialización de la naturaleza y la cultura, sino también de los riesgos, que hacen peligrar a humanos, animales y plantas del mismo modo. Tanto si pensamos en los miedos al agujero en la capa de ozono, la polución o la comida, la naturaleza está indisociablemente contaminada por la actividad humana. Esto es, el peligro común tiene un efecto igualador que reduce las barreras cuidadosamente levantadas entre clases, naciones, humanos, y el resto de la naturaleza, entre creadores de la cultura y criaturas de instinto o, por usar una antigua distinción, entre seres con y sin alma (Beck, 2000a, p. I8).

b. Esas amenazas, esos riegos, no pertenecen solamente a un país o región ni a una sola clase social, sino que son globales, planetarios:

... los riegos de la modernización (...) poseen una tendencia inmanente a la globalización. A la producción industrial le acompaña un universalismo de los peligros, independientemente de los lugares de su producción: las cadenas de alimentos conectan en la práctica a todos los habitantes de la Tierra. Atraviesan las fronteras. El contenido en ácidos del aire no ataca solo a las esculturas y a los tesoros artísticos, sino que ha disuelto ya desde hace tiempo las barreras aduaneras modernas. También en Canadá los lagos tiene mucho ácido, también en las cumbres de Escandinavia se mueren los bosques (Beck, 1988b, p. 42).

Es decir, si hay algo global y globalizador es el riesgo, no respeta fronteras, es universal por excelencia, no es patrimonio de un lugar sino del planeta:

Dicho con una fórmula: la miseria es jerárquica, el smog es democrático... objetivamente los riesgos despliegan dentro de su radio de acción y entre los afectados por ellos un efecto igualador. Ahí reside su novedosa fuerza política. En este sentido, las sociedades del riesgo no son sociedades de clase; sus situaciones de peligro no se pueden pensar como situaciones de clases, ni su conflictos como conflictos de clase (Beck, 1988b, p. 42).

c. Corolario de lo anterior, podemos decir que los riesgos tienen un efecto bumerang: ... los riegos afectan más tarde o más temprano a quienes lo producen o se benefician de ellos. Los riesgos muestran en su difusión un efecto social de bumerang: tampoco los ricos y los poderosos están seguros ante ellos" (Beck, 1988b, p. 43). 
d. Los riesgos se auto-reproducen, en el sentido de que un riesgo en un plano o dimensión genera otro riesgo:

La producción de riesgos de la modernización sigue el giro del bumerang. La agricultura intensiva industrial subvencionada con millardos hace crecer dramáticamente el contenido de plomo en la leche materna y en los niños no solo en las ciudades lejanas. También socava de muchas maneras la base natural de la producción agrícola: desciende la fertilidad de los campos, desaparecen animales y plantas necesarios para la vida, crece el peligro de la erosión del suelo (Beck, 1988b, p. 43-44).

e. Los daños ambientales no han sido provocados por la naturaleza, sino por el género humano a través de la ciencia y la tecnología: el uso de estas, en lugar de salvar a la humanidad, más bien amenazan con extinguirla. Beck formula esto claramente: ....se trata de un caso en el que la civilización se pone en peligro a sí misma, cosa no imputable a Dios, a los dioses ni a la naturaleza, sino a las decisiones humanas y los efectos industriales, es decir, a la tendencia de la civilización a configurar y controlar todo" (Beck, 1988a, p. 65).

f. Se produce una retroalimentación entre daños, la cual engendra una espiral de la destrucción:

Los daños ecológicos (por ejemplo, las inundaciones en Blangladesh) pueden desencadenar movimientos migratorios en masa, que pueden desembocar a su vez en conflictos bélicos. También otros Estados beligerantes amenazados por la derrota podrían recurrir, 'en última instancia', a la destrucción de plantas atómicas y químicas propias y ajenas para amenazar a las regiones fronterizas y a las grandes ciudades con la destrucción atómica (Beck, 1988a, p. 69).

g. Esos riesgos y los miedos que producen "unifican" a la humanidad, y se constituye una sociedad global. Esta sociedad global se forma, primero, porque los daños ambientales afectan a la totalidad del planeta $y$, segundo, porque hay una toma de consciencia mundial de que esos daños pueden acabar con el planeta (el miedo al "fin del mundo") y que hay que hacer algo al respecto.

Se trata de una teoría sociológica que, a diferencia de las anteriores, trata de explicar lo que sucede actualmente en el mundo a partir de lo ecológico o ambiental. Pero lo ecológico no se limita solamente a plantas y animales, reino vegetal y reino animal, sino que incluye hombres y mujeres.

h. Sociedad mundial no significa sociedad integrada:

La sociedad mundial no es, pues, ninguna megasociedad nacional que contenga -y resuelva en sí- todas las sociedades nacionales, sino un horizonte mundial caracterizado por la multiplicidad y la ausencia de integrabilidad, y que solo se abre cuando se produce y conserva en actividad y comunicación (Beck, 1988a, p. 31).

En la expresión 'sociedad mundial', 'mundial' significa según esto diferencia, pluralidad, y 'sociedad' significa estado de no-integración, de manera tal que (...) la sociedad mundial se puede comprender como una pluralidad sin unidad (Beck, 1988a, p. 29).

\section{Cosmopolitismo realmente existente versus proyecto cosmopolita}

En la obra de Beck, está claramente plasmada la idea de que la Globalización es inevitable, es un hecho, estemos o no de acuerdo con ella. Incluso acontece la "hermandad" de contrarios: el llamado "movimiento contra-globalización" utiliza los medios de la globalización (tecnologías de comunicación) para oponérsele, pero en esta acción, lo que hace es más bien fortalecer la misma globalización (2004, p. 376).

La globalización es una especie de enorme edificio que presenta un gran defecto de construcción: inexistencia de un Estado-gobierno mundial que controle los daños y riesgos sociales y ecológicos generados por la producción capitalista, que escapa a los Estados-nacionales y que opera ahora a escala mundial: ... Globalización significa también: ausencia de Estado mundial; más concretamente: sociedad mundial sin Estado mundial y sin gobierno mundial" (Beck. 1988a, p. 32). 
Que la globalización sea un hecho, una realidad, no significa sentarnos tranquilamente a contemplar sus daños y riesgos sociales y ecológicos: es necesario oponer a la globalización neoliberal o cosmopolitismo realmente existente el proyecto cosmopolita. A la globalización neoliberal, que tiene como valor y meta última el lucro, y la ganancia económica (aunque para alcanzarla haya que destruir la naturaleza y explotar a los seres humanos), hay que oponerle un proyecto cosmopolita que, según Beck, debe estar basado en la otredad de los otros, es decir, en el respeto a las culturas diferentes, el respeto al ambiente, el respeto a las generaciones presentes y futuras, el respeto a otras racionalidades y formas de pensamiento (2004, p. 373).

Al no existir un Estado-gobierno mundial, ¿quién va a llevar a cabo el proyecto cosmopolita? ¿No es esta una utopía, una bella idea, pero imposible de llevarla a la práctica? La respuesta de Beck va en el sentido de que este proyecto no es patrimonio de la figura clásica de los Estados-nacionales, sino más bien es impulsado por "nuevos" actores internacionales, tales como las organizaciones no gubernamentales:

Amnistía Internacional se autonombró fiscal global de las violaciones de derechos humanos en todo el mundo ante el tribunal global de la opinión pública, tribunal que ellos contribuyeron a crear en el sentido de una profecía que se autocumplía con la sola política de informar de hechos y casos (Beck, 2004, p. 391).

Ese proyecto puede ser llevado a la práctica por todos: ONG, individuos, grupos y asociaciones comunales, los mismos Estados que, aunque debilitados en la Globalización, todavía conservan protagonismo y cierto poder de decisión:

La fundación de nuevas organizaciones transnacionales (o el fortalecimiento de las existentes) que pudieran actuar como un contrapoder de los consorcios y bancos transnacionales y conseguir un marco normativo de reglas y líneas y códigos de comportamiento no solo para los gobiernos sino también para los actores de la economía mundial y las empresas privadas. De esta manera, los actores cosmopolitas que tiene el poder de negociar efectivamente las dimensiones no económicas del mercado global - la ecología, el clima, la enfermedad, la pobreza y la exclusión (así como vivir entre contradicciones)- darían testimonio de sí el régimen cosmopolita es una realidad o pura ideología (Beck, 2004, p. 399).

\section{Ciencia y tecnología dentro del proyecto cosmopolita}

¿Cómo hacer ciencia y tecnología enmarcadas dentro de un proyecto cosmopolita? ¿Cómo podemos evitar que se conviertan en un riesgo para la propia humanidad? La respuesta estriba implícitamente en el contexto en que se produjo la tragedia de Chernóbil: la energía atómica era pensada y utilizada como arma de ataque o de defensa contra un ataque de otro Estado o coaliciones de países en conflicto.

Lo que subyacía tras Chernóbil, y que continúa presente en buena parte del desarrollo de la ciencia y tecnología, son dos pilares: Estado y poder. Las creaciones se dan en el marco estrecho del país (y de las élites políticas y económicas predominantes en cada Estado), como medio de poder político (de control sobre otros Estados o de control sobre otros grupos dentro de un mismo país) y de poder económico (la tecnología como fuente de enriquecimiento o de ganancia). Es obvio que existen corporaciones transnacionales, las cuales van más allá del limitado espacio de los Estados, que producen ciencia y tecnología, pero también están guiadas por fines de lucro, incluyendo el vender sus productos a Estados para que estos los utilicen con fines político-militares.

El proyecto cosmopolita, como ya se apuntó, tiene como principio rector la "otredad del otro": ello significa que si el otro es semejante a mí, los criterios "egoístas" de Estado y de nacionalidad no deben ser orientadores de la ciencia y de la tecnología. Lo único que debería guiar a la ciencia y a la tecnología es la calidad de vida y el bienestar de la humanidad, más allá de Estados y nacionalidades.

¿Significa esto ser traidor a la patria a la cual pertenecemos, sea cual sea esta? La respuesta esta implícitamente contenida en las palabras de Martha Nussbaum:

Los estoicos no cesan de repetir que para ser ciudadano del mundo uno no debe renunciar a sus identificaciones locales, que pueden ser una gran fuente de riqueza vital. Por el contrario, lo que sugieren es que pensemos en nosotros mismos no como seres carentes de filiaciones locales, sino como seres 
rodeados por una serie de círculos concéntricos. El primero de estos círculos rodea el yo; el segundo la familia inmediata, y a este le sigue el de la familia extensa. A continuación, y por orden, el vecindario o los grupos locales; los conciudadanos y los compatriotas (y a esta lista podemos fácilmente añadir otros grupos basados en identidades étnicas, lingüísticas, históricas, profesionales, de género o sexuales). Alrededor de todos estos círculos está el mayor de ellos, el de la humanidad entera. Nuestra tarea como ciudadanos del mundo será «atraer, de alguna manera, estos círculos hacia el centro» (Hierocles, filósofo estoico, siglos I-II de nuestra era), haciendo que todos los seres humanos nos sean tan familiares como nuestros conciudadanos, y así sucesivamente. No debemos abandonar nuestros afectos e identificaciones particulares, ya sean estas de tipo étnico, religioso o basadas en el género. No es necesario que pensemos en ellas como algo superficial, puesto que, en parte, constituyen nuestra identidad. Podemos y debemos dedicarles una especial atención en la educación. Pero, al mismo tiempo, debemos también trabajar para hacer que todos los seres humanos formen parte de nuestra comunidad de diálogo y sean de nuestra incumbencia; basar nuestras deliberaciones políticas en esta comunalidad entrelazada y conferir una atención y un respeto especial al círculo que define nuestra humanidad (1999).
La mejor manera de orientar el desarrollo científico y tecnológico es esta: reconocer que somos un círculo, que estamos inmersos en una serie de círculos concadenados, como el símbolo del olimpismo: cada círculo mantiene su "propio yo" en la medida en que está articulado a otros círculos. Lo que hagamos en nuestro propio círculo, aunque sea para atacar a otro círculo o defendernos de él, puede volverse contra nosotros mismos: la radiación de Chernóbil afectó la vida humana, animal y vegetal de la misma Unión Soviética y de otros países.

Ello implica orientar la ciencia y la tecnología bajo un norte que vaya más allá de los Estados y poner la calidad de vida de la humanidad como su principio rector.

Pero la "otredad del otro" implica también el respeto de la naturaleza: la vida no es solamente humana, es también animal y vegetal, y el daño que hagamos a estos otros "círculos", tarde o temprano, tendrá un efecto bumerang sobre el género humano.

\section{Bibliografía}

Beck, U. (1988a). ¿Qué es la globalización? Falacias del globalismo, respuestas a la globalización. Barcelona: Paidós.

Beck, U. ( 1 988b). La sociedad del riesgo. Barcelona: Paidós.

Beck, U. (2000) Retorno a la teoría de la 'sociedad del riesgo'. Estudios. Boletín de la A.G.E., (30).

Beck, U. (2004). Poder y contra poder en la era global. La nueva economía política mundial. Barcelona: Paidós.

Delanty, G. (2008). La imaginación cosmopolita. Revista ClDOB d'Afers Internacionals, (82-83).

Guéhenno, J. (1995). El fin de la democracia. La crisis política y las nuevas reglas del juego. Barcelona: Paidós.

Nussbaum, M. (1999). Los límites del patriotismo: Identidad, pertenencia y "ciudadanía mundial". Barcelona: Paidos. 